\title{
Determination of Heavy Metals in Soils, Sediments and Geological Materials by ICP-AES and ICP-MS
}

\author{
Christoph Moor $^{1, *}$, Theopisti Lymberopoulou ${ }^{2}$, and Volker J. Dietrich ${ }^{3}$ \\ ${ }^{1}$ Swiss Federal Laboratories for Materials Testing and Research (EMPA) Überlandstrasse 129, CH-8600 Dübendorf, Switzerland \\ 2 Institute of Geology and Mineral Exploration (IGME), Chemical Division, 1st km Markopoulou Ave., GR-19002 Peania, Greece \\ ${ }^{3}$ Institute of Mineralogy and Petrography, Swiss Federal Institute of Technology (ETH) Sonneggstrasse 5, CH-8092 Zürich, Switzerland
}

\begin{abstract}
Sixteen soil and sedimentary geological reference materials were analysed for As and the heavy metals $\mathrm{Cd}, \mathrm{Co}, \mathrm{Cr}, \mathrm{Cu}, \mathrm{Ni}, \mathrm{Pb}$ and $\mathrm{Zn}$ by inductively coupled plasma-atomic emission spectrometry (ICP$\mathrm{AES}$ ) and inductively coupled plasma-mass spectrometry (ICP-MS) in combination with total and partial dissolution of the samples. It can be demonstrated that none of the modern ICP methods is completely free from analytical problems. This applies in particular when the concentrations are close to the detection limits (e.g. in ICP-AES) and is mainly due to the wide variation in the bulk composition of soils resulting in complex matrix effects (e.g. in ICP-MS). In order to determine the extent of soil pollution by heavy metals, both partial and total dissolution have to be performed prior to analysis.
\end{abstract}

Key words: Soil analysis; heavy metals; inductively coupled plasma-atomic emission spectrometry; inductively coupled plasma-mass spectrometry.

Soil is composed of mineral constituents, organic matter (humus), living organisms, air and water, and it regulates the natural cycles of these components. If filters and purifies water and it degrades and stores materials. Heavy metals ( $\mathrm{Fe}, \mathrm{Mn}, \mathrm{Ni}, \mathrm{Co}, \mathrm{Zn}, \mathrm{Cu}, \mathrm{Cr}, \mathrm{V}$, $\mathrm{Ti}, \mathrm{Cd}, \mathrm{Hg}$, Mo and other trace metals) as well as As, $\mathrm{Se}$ and $\mathrm{F}$ occur naturally in soils, which are formed by geological processes, such as alteration and erosion of the geological underground materials. Besides the

\footnotetext{
* To whon correspondence should be addressed
}

parent material, the sources of contamination in soils are multifarious, and include agricultural and industrial pollution [1]. The high levels of civilisation-related soil pollution have recently become a major issue and the chemical analysis of soils is important for environmental monitoring and legislation [2]. In order to develop risk assessment and sustainable development concepts for contaminated soils, accurate determinations of concentrations of harmful and toxic elements are needed [3]. The question whether an aqua regia extraction can lead to acceptable results or a total dissolution by an attack with hydrofluoric acid is always necessary to establish total concentrations has been discussed controversially $[4,5]$.

In the present study, sixteen soil and sedimentary geological reference materials were treated by microwave assisted digestion and open digestion. The resulting solutions were analysed by ICP-AES and ICP-MS in two different laboratories. This scheme was used in order to separate sample preparation effects from problems occurring during the analysis.

\section{Experimental}

The samples investigated were MAG-1 (USGS, Marine mud, bottom sediment, Wilkinson Basin, Gulf of Maine); SCo-1 (USGS, Cody shale, Natrona County, Wyoming, USA); SDC-1 (USGS, mica schist, muscovite-quartz schist, Rock Creek Park, Washington D.C.); SGR-1 (USGS, oil shale, Green River Formation, Wyoming, USA); SO-1 (CCRMP, regosolic clay soil, Hull, Québec, Canada); SO-2 (CCRMP, podzalic B horizon soil, Montmorency forest, Québec City, Canada); SO-3 (CCRMP, calcareous C horizon soil, Guelph, Ontario, Canada); SO-4 (CCRMP, chermoyemic A horizon soil, Saskatoon, Saskatchewan, Canada); the Canadian sediments LKSD-1 (CCRMP, Joe and Brady Lakes); LKSD-2 (CCRMP, 
Calabogie Lake); LKSD-3 (CCRMP, Calabogie Lake); LKSD-4 (CCRMP, Big Gull, Key and Sea Horse Lake); STSD-1, STSD-2, STSD-3 and STSD-4 (all from CCRMP, Lavant Creek and Hirok Stream).

The samples were dried at $105^{\circ} \mathrm{C}$ for $3 \mathrm{~h}$. About $0.2 \mathrm{~g}$ of sample was accurately weighed into a container made of PFA (a perfluoroalkoxy polymer), which was then placed in a microwave pressure vessel. After addition of $4 \mathrm{ml}$ of concentrated nitric acid and $0.5 \mathrm{ml}$ of concentrated hydrofluoric acid, the samples were digested by using a microwave power progressively increasing up to $400 \mathrm{~W}$ during $40 \mathrm{~min}$. After cooling, the solutions were accurately diluted to $100 \mathrm{ml}$ with water. In addition, an open digestion in a glass beaker was performed with $0.5 \mathrm{~g}$ of sample, accurately weighed, by heating with $12 \mathrm{ml}$ of aqua regia for $45 \mathrm{~min}$, followed by evaporation almost to dryness. To the hot residue,
$2.5 \mathrm{ml}$ of concentrated hydrochioric acid and $2.5 \mathrm{ml}$ of hydrogen peroxide were added, followed by accurate dilution to $50 \mathrm{ml}$ with water. One replicate per digestion method was done for each sample.

All solutions were split for the analysis in the two laboratories. They were analysed directly by ICP-AES (at IGME). For ICP-MS (at EMPA), all solutions were additionally diluted with water to give a final total dissolved solids concentration of $1 \mathrm{~g} / \mathrm{l}$, corresponding to a dilution factor of 2 for the solutions from the microwave digestion and of 10 for the solutions from the open digestion.

ICP-AES analyses were done with a Jobin-Yvon 38 spectrometer, using the following interference-free but not most sensitive wavelengths: Zn $213.856 \mathrm{~nm}, \mathrm{Cd} 214.438 \mathrm{~nm}, \mathrm{~Pb} 220.353 \mathrm{~nm}$, Ni $231.604 \mathrm{~nm}, \mathrm{Cr} 267.716 \mathrm{~mm}$ and $\mathrm{Cu} 324.754 \mathrm{~nm}$. For ICP-MS analyses, $20 \mu \mathrm{g}$ of $\mathrm{Rh}$ per litre was added as an internal standard.
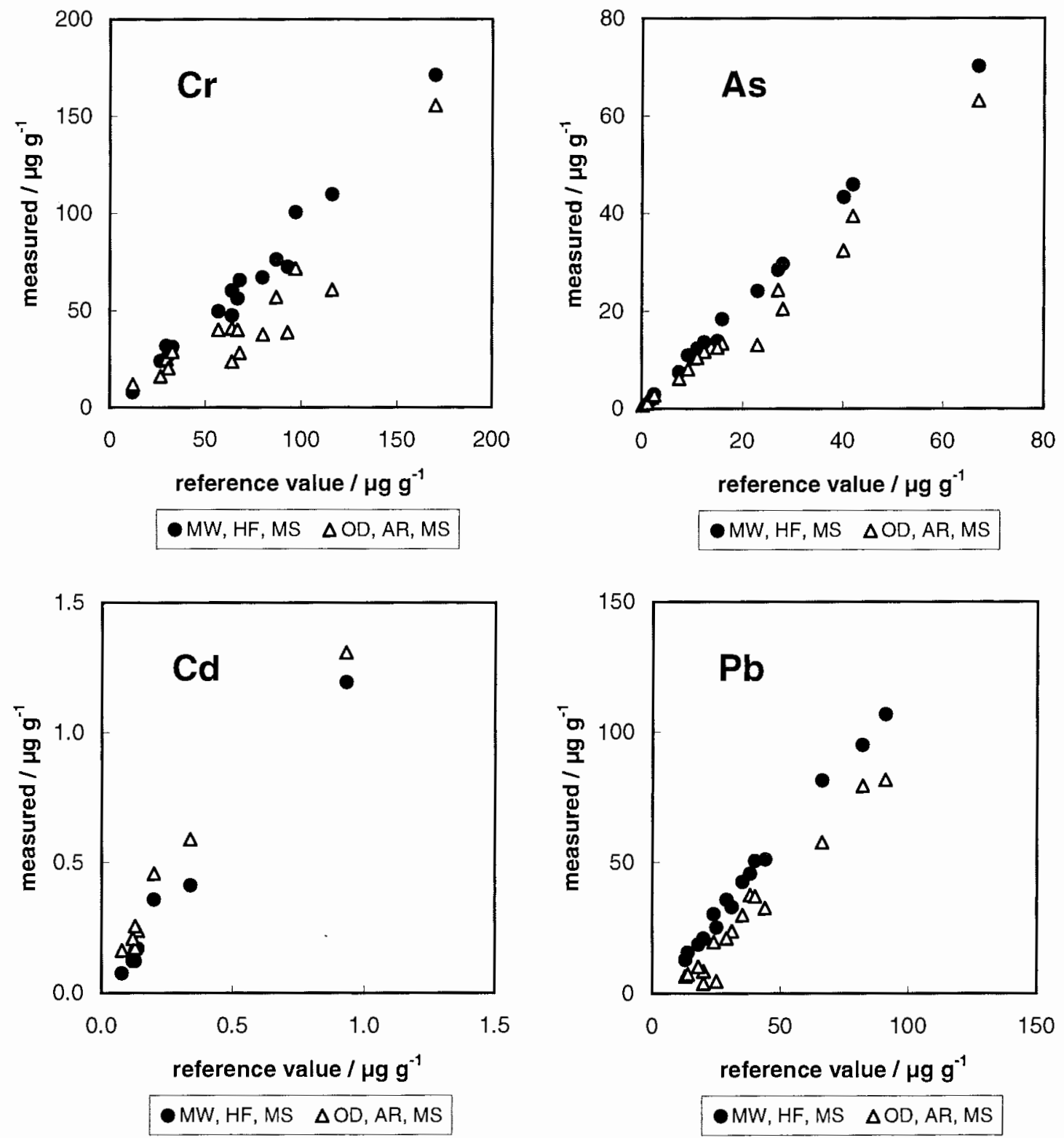

Fig. 1. Results by different digestion methods compared to reference values from [10, 11]. Abbreviations (used in all figures): $M W, H F$ microwave digestion with $\mathrm{HNO}_{3} / \mathrm{HF} ; O D, A R$ open digestion with $\mathrm{HCl} / \mathrm{HNO}_{3} ; M S$ determined by ICP-MS; AES determined by ICP-AES 
The samples were analysed with an ELAN 6000 instrument by using the isotopes ${ }^{52} \mathrm{Cr},{ }^{59} \mathrm{Co},{ }^{60} \mathrm{Ni},{ }^{63} \mathrm{Cu},{ }^{66} \mathrm{Zn},{ }^{75} \mathrm{As},{ }^{114} \mathrm{Cd}$ and ${ }^{208} \mathrm{~Pb}$.

\section{Results and Discussion}

Figure 1 shows a good correlation between reference and measured values obtained by the microwave digestion method. In general, the aqua regia extraction can leach only a fraction of the total metal content and leads to lower results. This is the case for $\mathrm{Cr}$, which is mostly present in mineral form. For $\mathrm{Cd}$, the deviations from the ideal line with a slope of unity can be explained by the larger uncertainty of both the measured and the reference values at these concentration levels. A slight positive bias to the theoretical slope of one could possibly be caused by a spectral interference by ${ }^{98} \mathrm{Mo}^{16} \mathrm{O}^{+}$. Both digestion methods give a complete extraction for molybdenum.

The comparison between the different instrumental methods is displayed in Fig. 2. In general, a good agreement is found for the results obtained by the two independent methods in the two different laboratories. Spectral interference of ${ }^{40} \mathrm{Ca}^{16} \mathrm{O}^{+}$with ${ }^{60} \mathrm{Ni}^{+}$could be excluded, since the application of a correction factor based on the previously measured ratio of $\mathrm{CaO}^{+} / \mathrm{Ca}^{+}$ and the $\mathrm{Ca}$ signal of the sample did not significantly change the results. That is confirmed by the good linearity compared to ICP-AES. However, the ICPAES results for the MW, HF samples show some irregularities for $\mathrm{Ni}$ and $\mathrm{Pb}$ since their concentrations in these solutions were close to the detection limits of the
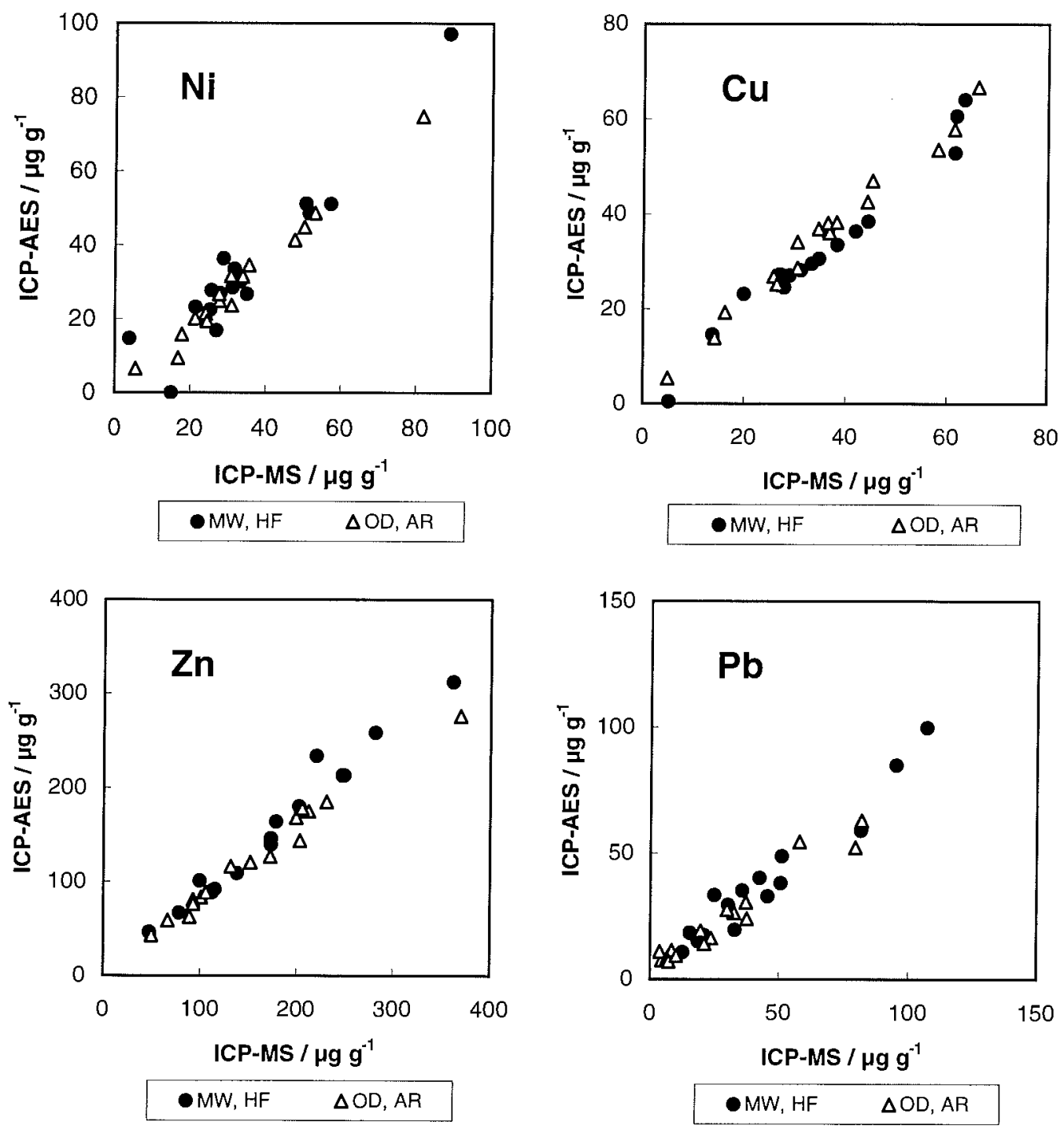

Fig. 2. Comparison of analytical methods, applied in two different laboratories: ICP-AES (IGME) versus ICP-MS (EMPA) 


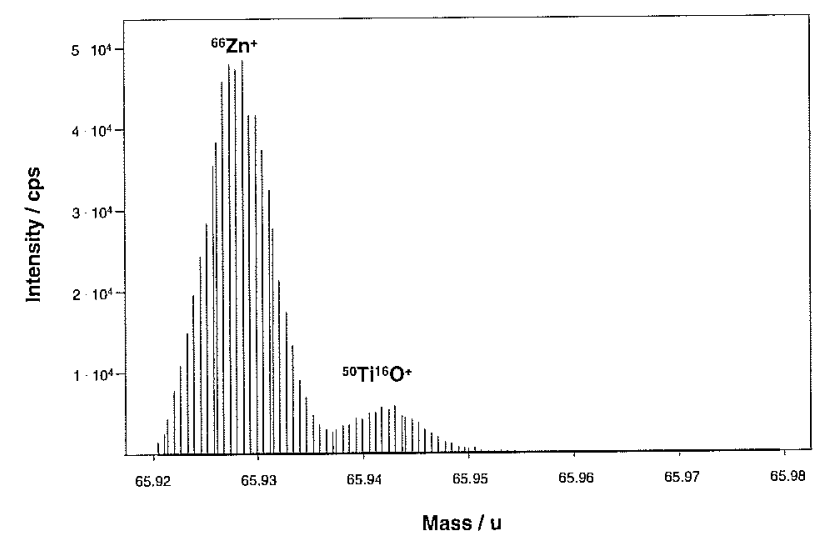

Fig. 3. Mass spectrum of ${ }^{66} \mathrm{Zn}$ in SO-4, measured at a nominal mass resolution 4000 for diagnostic purposes, using a sector field ICP-MS
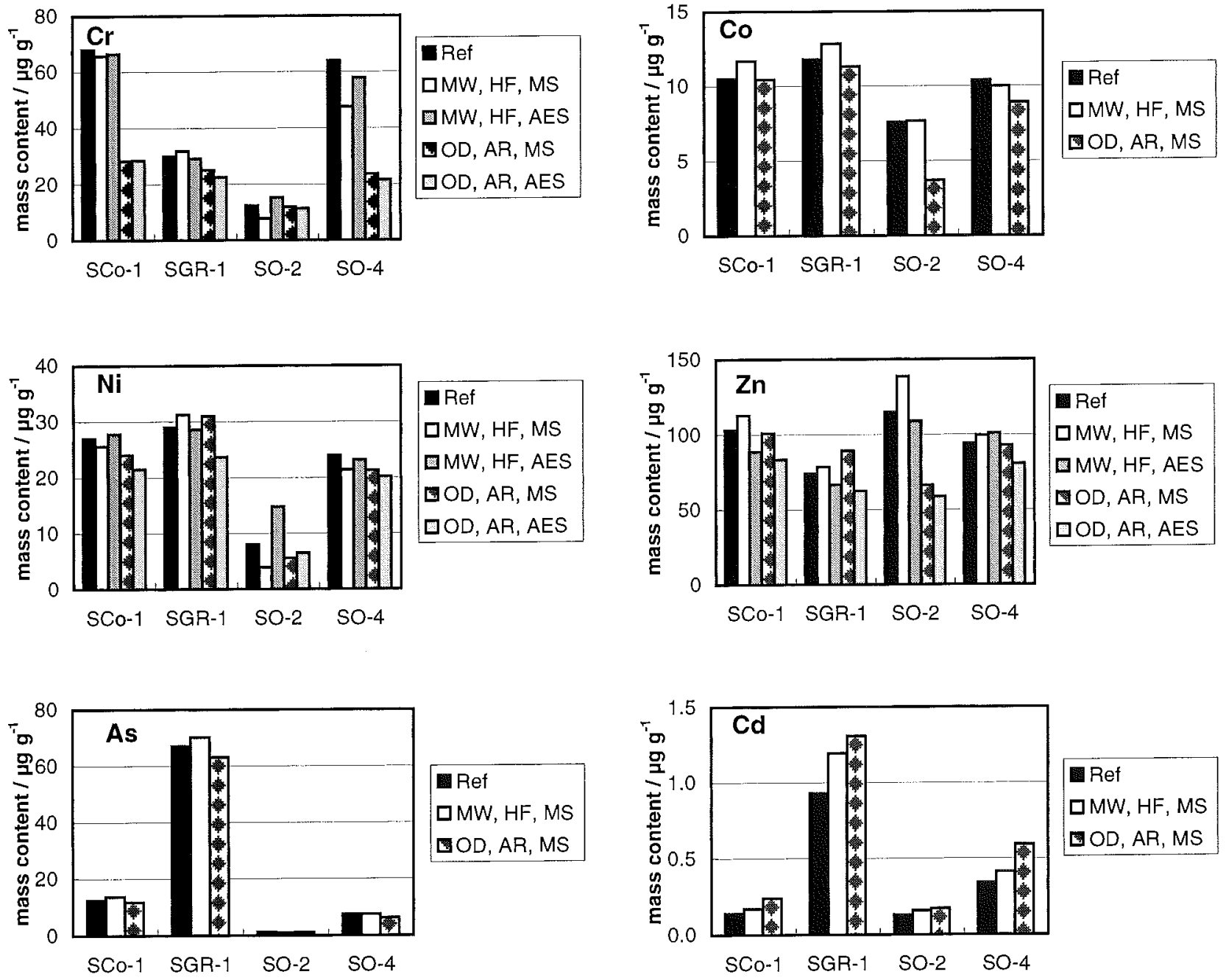

method, owing to the higher dilution factor of these solutions. In some. samples, ICP-MS determinations of $\mathrm{Zn}$ seem to yield higher values than with ICP-AES (and the reference value) which can possibly be explained by spectral interference by ${ }^{50} \mathrm{Ti}^{16} \mathrm{O}^{+}$or ${ }^{34} \mathrm{~S}^{16} \mathrm{O}_{2}^{+}[6,7]$.

An extremely valuable tool for identifying such interferences is a mass spectrometer providing a mass resolution high enough to separate the isotopes from the interfering polyatomic ions. In this study, we had the opportunity to measure mass spectra of all analytes of interest in the sample SO-4 by using a sector-field ICP-MS (ELEMENT2, Finnigan MAT). The spectrum of the mass region of ${ }^{66} \mathrm{Zn}$ is shown in Fig. 3. Based on the accurate mass of the peaks, the interfering peak can be identified as ${ }^{50} \mathrm{Ti}^{16} \mathrm{O}^{+}$. With a quadrupole ICP-MS such as the ELAN6000 used for the quantitative
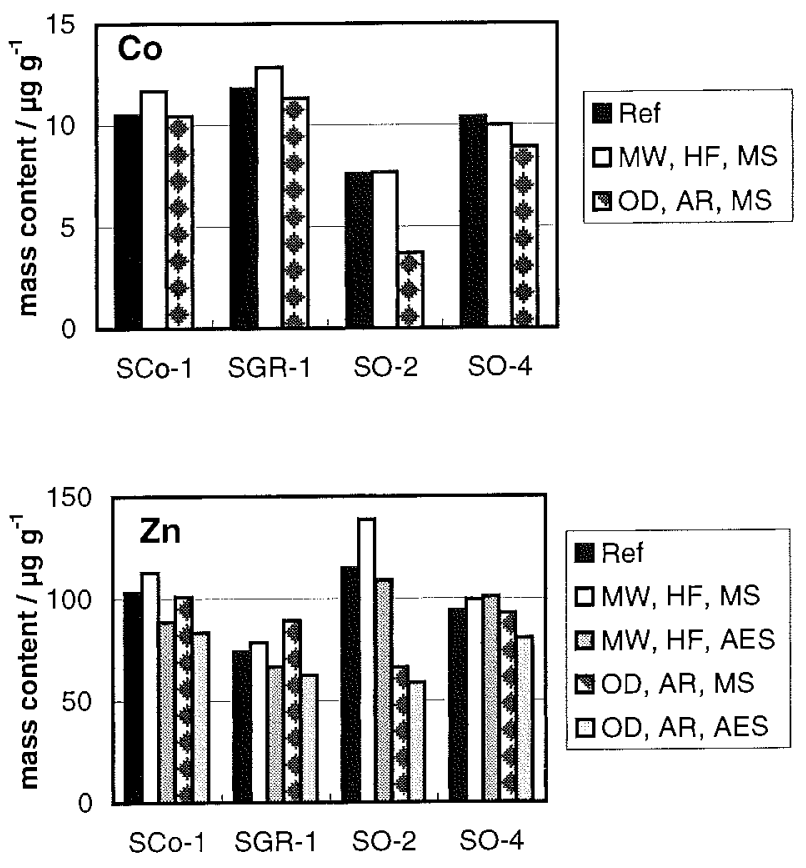

Fig. 4. Summary of all results for four selected reference materials 
analyses, basically the same oxides and polyatomic species are formed. However, their rate of formation depends strongly on the experimental conditions and cannot directly be transferred for use from one instrument to another. Unfortunately, the separation of the mentioned ${ }^{98} \mathrm{Mo}^{16} \mathrm{O}^{+}$from ${ }^{114} \mathrm{Cd}$ would require a resolution of more than 37000 and is therefore not possible with this type of spectrometer [8].

A comprehensive comparison of reference values, digestion methods and analysis techniques for four selected soil samples (SCo-1, SGR-1, SO-2 and SO-4) is shown in Fig. 4. It is obvious that the influence of the digestion method is much higher than the influence of the measurement technique. This effect is observed most clearly for $\mathrm{Cr}$. A lower Co value was found by the open digestion with aqua regia in just one sample. The reason for that effect is not clear, since the other values from the two digestion methods are all consistent, but the matrices of all the samples show a broad variety, and the matrix effects need to be investigated more closely.

In discussing analyses of reference materials, it is important to take into account the uncertainties of the measurements. This is shown in Fig. 5, where the results for $\mathrm{Cu}$ are displayed in the same way as in Fig. 4 , but with an uncertainty stated. In the case of the reference materials, this is the $95 \%$ confidence limit. For the ICP-MS measurements, the uncertainty was estimated according to the EURACHEM guide "Quantifying Uncertainty in Analytical Measurement" [9]. Different assumptions were made for the estimation: that the sample homogeneity is perfect, the digestion complete, no contamination or interferences occur, the mean Cu concentration was $50 \mu \mathrm{g} / \mathrm{g}$ and the maximum instrumental drift was $5 \%$. A coverage factor of 2 was applied. For the ICP-AES measurements, the uncertainty was estimated on the basis of

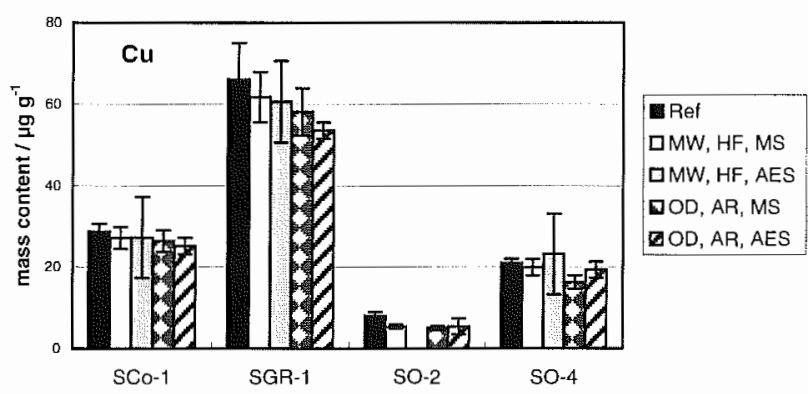

Fig. 5. Comparison of confidence limits of reference values and measurement uncertainty signal stability. The results agree well, since $\mathrm{Cu}$ is easily extractable even under the milder digestion conditions. The relatively high uncertainty of the ICPAES measurements for the samples digested by the microwave method with HF (MW, HF, AES in Fig. 5) compared to the open digestion samples is a consequence of the fact that the solutions from microwave digestion are less concentrated than those from the open digestion, resulting in concentrations that are close to the detection limit. For the sample SO-2, the apparent result was below the detection limit.

It is obvious that modern ICP techniques based on optical atomic emission or mass spectrometry can be used to determine heavy metals in soils, if the effects of digestion, matrix and interferences are correctly eliminated. However, both techniques have their drawbacks and the validity of a result has always to be checked. Common problems are spectral interferences of matrix components. In this study, oxides of $\mathrm{Ti}$ and Mo presumably caused too high results for $\mathrm{Zn}$ and Cd. This application of independent methods and the use of certified reference materials are valuable tools for method validation. The choice of sample digestion is the dominant source of systematic error, since extraction from siliceous materials by aqua regia is always liable to be incomplete.

Today, many legal regulations concerning pollutants in soils are based on extractable concentrations. This approach can lead to wrong results, since an uncontrolled amount of heavy metals can be extracted from the fraction naturally present from rock erosion. Techniques for total metal determination are available and should be applied in combination with partial extraction techniques, the latter being comparable to the conditions of the natural processes leading to the presence of metals in the samples.

Acknowledgements. The authors thank Panagiotis Papaneofytou (IGME), Roger Ruitti (IMP, ETH) and Judith Kobler (EMPA) for helping in the digestion of the samples.

\section{References}

[1] M. P. Tuchschmid, V. Dietrich, P. Richner, P. Lienemann, A. Desaules, R. Kündig, R. Vogler, Federal Office of Environment, Forests and Landscape (BUWAL). Umweltmaterialien Nr. 32, Bern, 1995.

[2] M. R. Carter, Soil Sampling and Methods of Analysis. Canadian Society of Soil Science, Lewis, Boca Raton, 1993.

[3] Verordnung über Belastungen des Bodens (VBBo) 814.12 vom 1. Juli 1998. Der Schweizerische Bundesrat, gestützt auf die Artikel 29, 33 Absatz 2, 35 Absatz 1 und Absatz 391 
des Umweltschutzgesetzes vom 7. Oktober 1983 (Swiss law for environmental protection).

[4] I. L. Marr, P. Kluge, L. Main, V. Margerin, C. Lescop, Mikrochim. Acta 1995, 119, 219.

[5] P. Krause, B. Erbslöh, R. Niedergesäß, R. Pepelnik, A. Prange, Fresenius J. Anal. Chem. 1995, 353, 3.

[6] E. H. Evans, J. J. Giglio, J. Anal. At. Spectrom. 1993, 8, 1.

[7] A. Montaser, Inductively Coupled Plasma Mass Spectrometry. Wiley-VCH, New York, 1998.
[8] I. Rodushkin, T. Ruth, J. Anal. At. Spectrom. 1997, 12, 1181.

[9] EURACHEM, Quantifying Uncertainty in Analytical Measurement. Laboratory of the Government Chemist, London, 1995.

[10] E. Gladney, Reference Value Confidence Limit Categories, Geostandards Newsl., 1998, http://www.geostandards.lanl.gov/GN_rm_confidence_limits.htm.

[11] K. Govindaraju, Geostandards Newsl. 1994, 18, (Special Issue). 